\title{
Trust, tribalism and tweets: has political polarization made science a "wedge issue"?
}

Brian Helmuth ${ }^{1,2^{*}}$, Tarik C. Gouhier ${ }^{1}$, Steven Scyphers ${ }^{1}$ and Jennifer Mocarski ${ }^{1,2}$

\begin{abstract}
Background: Political polarization remains a major obstacle to national action on global climate change in the United States Congress, and acceptance of anthropogenic drivers strongly differs between Republicans and Democrats. But has overall interest in science also become ingrained into partisan identity, even among national political figures tasked with making ostensibly science-based policy decisions? Social media outlets such as Twitter have become a popular means of exchanging information and of portraying a carefully crafted public image. We analyzed the 78,753 unique Twitter accounts followed by U.S. senators to gauge their interests as well as the public images that their offices project to the public. In particular, we examined correlations between follows of science-related accounts and recent votes on a series of amendments defining the "sense of the Senate" on global climate change (GCC). Drawing from these social networks, we discuss how political polarization is strongly linked with the role that science - and climate science in particular - plays in the political process.

Results: Our analyses show that Twitter social networks reflect political affiliation and polarization, with Senate Republicans and Democrats belonging to distinct and semi-isolated sub-networks. Notably, while follows of science-related organizations were low overall, these sub-networks were characterized by very different levels of interest in science, with Senate Democrats three times more likely to follow science-related Twitter handles than Republicans. This suggests that overt interest in science may partly define party identity. Hence, instead of being viewed as a neutral source of objective information, science may now be considered a special interest in U.S. politics. Notably, however, Republican senators who crossed party lines to vote "yea" on an amendment associated with the Keystone Pipeline bill stating that humans contribute to GCC are more similar to Democrats in their science follows than they are to their fellow Republicans.
\end{abstract}

Conclusions: Our results strongly suggest that overt interest in science may now primarily be a "Democrat" value. However, opportunities exist to inject scientific information into political discussion by targeting key individuals and organizations connected to both sides of the aisle.

Keywords: Global climate change, Politics, Partisanship, Science communication, Social media

\section{Background}

The last decade has seen repeated calls for scientists to communicate their work to legislators in order to promote the inclusion of "usable" scientific information in policy decisions $[1,2]$. But to what extent are political leaders interested in listening to scientists, particularly when contending with politically polarized issues such as global climate change (GCC) [3]? Accessible scientific information has the potential to cut through political

\footnotetext{
* Correspondence: b.helmuth@neu.edu
${ }^{1}$ Marine Science Center, Northeastern University, Nahant, MA 01908, USA
${ }^{2}$ School of Public Policy and Urban Affairs, Northeastern University, Boston,

* Correspondence: b.helmuth@neu.edu
${ }^{1}$ Marine Science Center, Northeastern University, Nahant, MA 01908, USA
${ }^{2}$ School of Public Policy and Urban Affairs, Northeastern University, Boston,

* Correspondence: b.helmuth@neu.edu
${ }^{1}$ Marine Science Center, Northeastern University, Nahant, MA 01908, USA
${ }^{2}$ School of Public Policy and Urban Affairs, Northeastern University, Boston, MA 02115, USA
}

(c) 2016 Helmuth et al. Open Access This article is distributed under the terms of the Creative Commons Attribution 4.0 International License (http://creativecommons.org/licenses/by/4.0/), which permits unrestricted use, distribution, and reproduction in any medium, provided you give appropriate credit to the original author(s) and the source, provide a link to the Creative Commons license, and indicate if changes were made. The Creative Commons Public Domain Dedication waiver (http://creativecommons.org/publicdomain/zero/1.0/) applies to the data made available in this article, unless otherwise stated.

polarization and gridlock by presenting objective facts to counter subjective opinions, thus facilitating the ability of legislators to make science-based decisions regarding policies and funding priorities $[4,5]$. This need for science-based policy has become particularly dire in the United States where members of Congress are debating the science and societal implications of GCC, while at the same time some are attempting to wrest decisions regarding scientific funding priorities away from heads of national science agencies such as NSF and NASA $[6,7]$. While these observations are independently alarming, several questions important for diagnosing and overcoming the gridlock remain unanswered. For 
instance, has science overall become polarized to the extent that outward interest in science (and not just climate science) might harm partisan identity? Similarly, does interest in scientific information actually influence political decision making, or are such decisions made mostly on the basis of partisan group identity? Answers to these questions have the potential to help maximize the ability of the scientific community to effectively communicate both environmental and climate science [8]. Both Republicans and Democrats have been accused by their political opponents as being "anti-science," to a large extent on the basis of policy decisions regarding issues as diverse as climate change, evolution, vaccination and genetically modified organisms $[9,10]$. Several studies have suggested that conservatives have become increasingly distrustful of science [11] and political differences among members of the American public in their level of trust in climate science and "belief" in anthropogenic climate change have been well-established $[12,13]$. Other studies, however, have suggested that such generalizations are too simplistic, arguing for example that self-identified economic (as opposed to social) conservatives may be as or more scientifically literate than economic leftists [14]. Explorations such as these are important if we as scientists hope to engage constructively with the multiple publics on pressing societal issues such as GCC.

While a growing body of literature has examined perceptions of and interest in science among the lay publics, we know considerably less of how such differences may play out among elected officials, in part because they may be less willing to discuss their personal views openly. We analyzed the public Twitter profiles of U.S. senators as a window into these questions. The Twitter handles that a user follows serve as an indicator of the people, organizations, and issues in which the user is interested $[15,16]$, and are arguably an objective reflection of the public image a user wishes to portray. Twitter is thus now commonly used by the offices of U.S. political leaders not only for information sharing and issuing "calls to arms" to their constituents, but perhaps even more importantly serves as a platform for self-promotion and a public expression of their core values [17]. Social media platforms like Twitter also offer a means of rapidly disseminating information, and instantly sharing links to news stories of interest between a user and their followers. In this way, networks or communities of users with common interests often form, within which information is then shared [17]. For example, Twitter is a place where interested followers can be alerted to scientific breakthroughs in real-time and where "buzz" about newly published research is measurable [18]. A recent study by the Pew Research Center found that $63 \%$ of Twitter users report that they use the platform as a source of news, up from $52 \%$ in 2013 and almost twice that of Facebook users [19]. The accounts that a user opts to follow thus determine the information that she or he sees on Twitter, as well as a statement of the other users with which the person wishes to be associated publically.

A 2015 survey by Jasny and colleagues [20] emphasized that in political spheres information on climate change often reverberates within a series of "echo chambers" with relatively few opportunities for cross-fertilization. Analyses of the general public based on Twitter, in contrast, suggest that while information on political issues is exchanged primarily among users with similar ideologies, information regarding other current events can be more dynamic and at least initially starts as a "national conversation" that may eventually devolve into partisan bickering [16]. And, while some studies have demonstrated substantial differences among Republicans and Democrats in the intensity to which they respond negatively to scientific information that conflicts with their world view [21], others have suggested that "...scientific recommendations on public policy are taken seriously by partisans of all stripes" [22]. While numerous surveys have documented strong partisan differences in understanding and acceptance of GCC among members of the general public $[12,13]$ and have pointed to the role of partisan media in widening such gaps [23], less is known about how political leaders receive and share such information, especially using increasingly important social media platforms such as Twitter. Specifically, are political leaders exposed to similar scientific information but responding to it based on partisan identity [21], or are they interested in and exposed to information from fundamentally different sources, as shaped by the communication networks to which they belong $[20,24]$ ? Has interest and trust in science- and notably not just climate science- truly become a partisan wedge issue in the 21st century?

We analyzed the 78,753 unique Twitter accounts followed by U.S. senators to gauge their interests as well as the public images that their offices project to the public. We were particularly interested in determining if higher levels of overt interest in and exposure to science and climaterelated Twitter feeds had any correlation with senators' positions on GCC. We took advantage of votes (made in January 2015) on a series of amendments associated with the Keystone oil pipeline legislation clarifying the U.S. Senate's position on GCC. We then used ordination and network analysis to identify influential people and organizations that might best provide an avenue for injecting scientific information into the network(s).

\section{Results}

Twitter follows are diagnostic of political tribalism

An ordination analysis of senators' Twitter accounts showed a strong partisan affinity within each political party, with minimal overlap between Democrats and Republicans with respect to whom they follow on Twitter 
(Fig. 1). Results also showed a strong pattern of mutual follows among senators within each party, creating two independent subnetworks where the limited information that is injected into the inner circle of each political party is shared. This is consistent with recent surveys showing how information is disproportionately shared among people with similar political ideologies [20]. An analysis of senators' direct communication network (mutual follows among senators, Fig. 2a) and indirect affiliation network mediated by shared interests (i.e., commonalities in the Twitter accounts that senators follow, Fig. 2b) was used to quantify the degree of political polarization. Both networks exhibited distinct clusters or communities of senators within each network being significantly associated with political party (communication network: $\chi^{2}=62.47$, $d f=1, \quad p$-value $<0.001$; affiliation network: $\chi^{2}=61.68$, $d f=1, p$-value $<0.001$; Fig. 2). Specifically, the community detection algorithm correctly identified $100 \%$ of
Senate Democrats and $88 \%$ of Senate Republicans in the communication network, and $97 \%$ of Senate Democrats and $90 \%$ of Senate Republicans in the affiliation network. This is indicative of strong tribalism in both the communication and affiliation networks, with politically likeminded senators forming isolated groups. There was no significant difference in median eigenvector centrality, a measure of node influence, between Democrats and Republicans in the affiliation network. This implies that the pattern of clustering and isolation is not driven by interparty differences in senator influence on the affiliation network (Fig. 3; Mann-Whitney $U$ test, $U=1128.5$, $p$-value $=0.09)$. However, the median eigenvector centrality of Senate Republicans (0.73) was significantly greater than that of Senate Democrats (0.57) in the communication network (Fig. 3; Mann-Whitney $U$ test, $U=1370$, $p$-value $=0.0001)$, suggesting that Senate Republicans are more likely to follow influential nodes than Senate

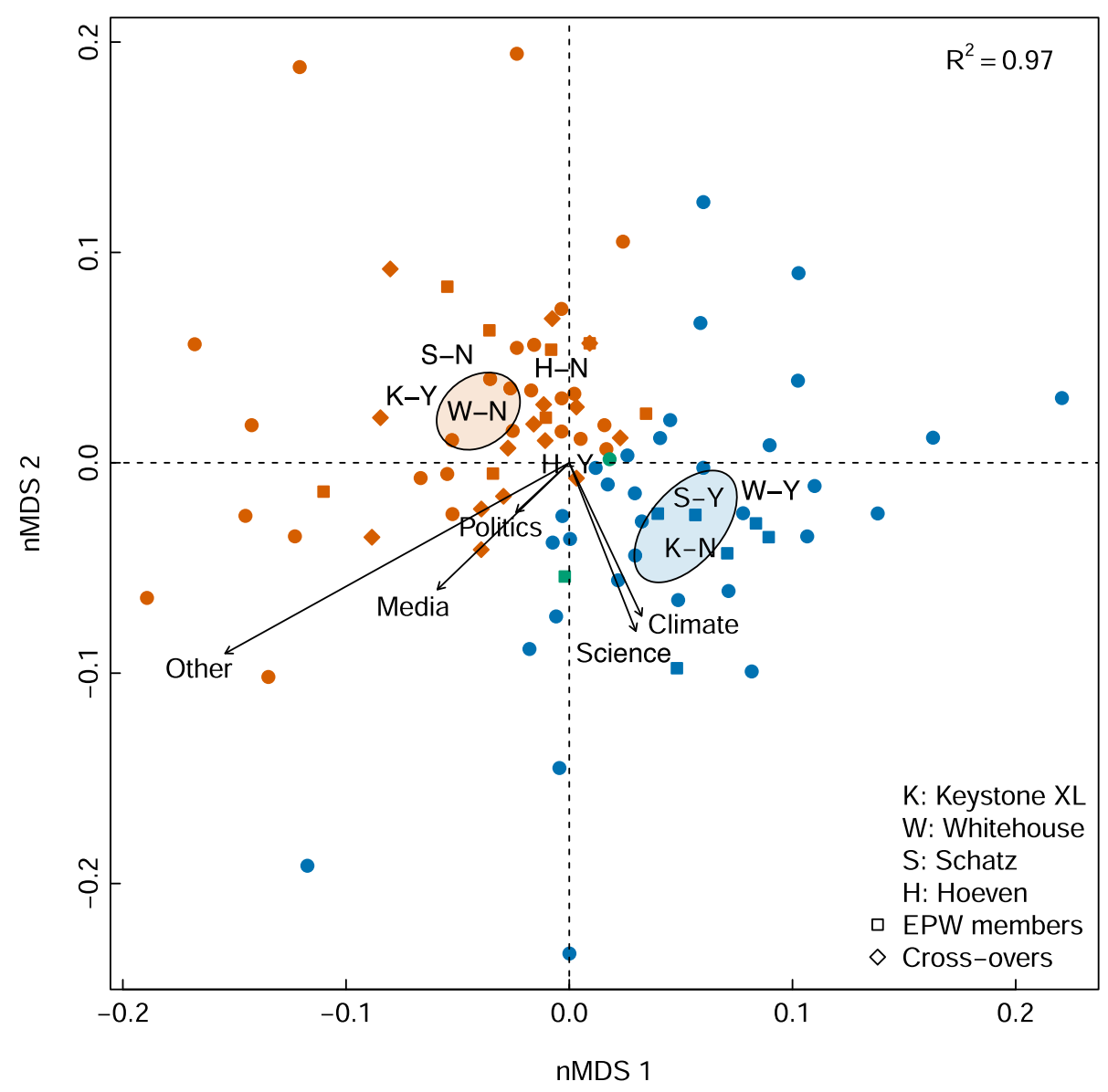

Fig. 1 Ordination analysis (nMDS) of Twitter accounts followed by U.S. Senate Republicans (in red) and Senate Democrats (in blue). Letters overlain on the figure indicate senators who voted "Yea" or "Nay" on the overall Keystone pipeline bill (K) or the subsequent amendments to the bill put forth by Sen. Whitehouse (M), Sen. Schatz (S) and Sen. Hoeven (H). The 15 Senate Republicans who crossed party lines on the Sen. Hoeven amendment are indicated by red diamonds, and members of the U.S. Senate Committee on Environment and Public Works Committee are designated by squares with color indicating political party. Vectors represent degree and magnitude of polarity in propensity to follow Twitter handles categorized as Science, Climate, Politics, Media and Other 
(a) Communication network

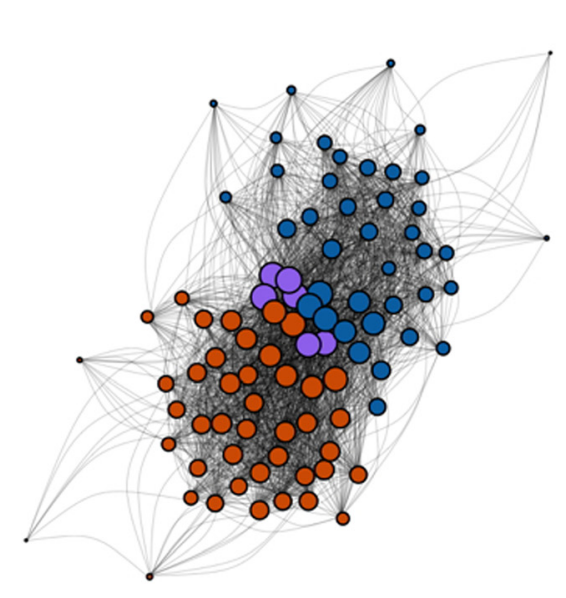

(b) Affiliation network

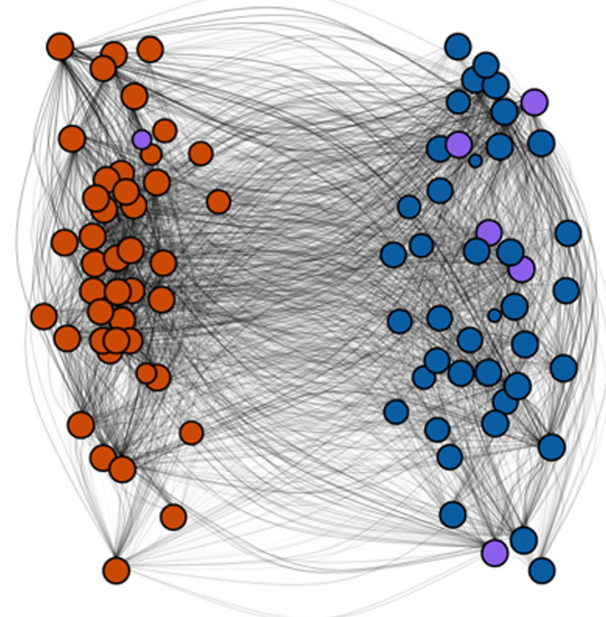

Fig. 2 Communication and affiliation subnetworks of senators. Community detection algorithms based on leading eigenvector centrality show that the senators in communication (a) and affiliation (b) networks cluster based on party membership (red for Republican, blue for Democrat). The community detection algorithms correctly identified $100 \%$ of Senate Democrats and $88 \%$ of Senate Republicans in the direct communication network, and $97 \%$ of Senate Democrats and $90 \%$ of Senate Republicans in the affiliation network. Misidentified senators are plotted in purple. The size of the nodes is proportional to senators' leading eigenvector centrality. The modularity scores, which describe the degree of compartmentalization in the network, are 0.165 for the community network and 0.093 for the affiliation network. These networks are significantly more modular than expected based on networks generated by randomly shuffling the accounts that each senator follows $(p$-value $<0.001)$

Democrats. There was no significant difference in the heterophily scores (a measure of the degree to which each Senator follows members of the opposite party) of Senate Republicans and Democrats based on the average weight of their connection to members of a different party in both the communication network $(F=0.178$, $d f=1, p$-value $=0.674$; Table 1$)$ and the affiliation network $(F=0.312, d f=1, p$-value $=0.578$; Table 2$)$. This shows that Senate Democrats and Senate Republicans are both contributing to the observed polarization reflected on Twitter.

However, there is a high degree of heterogeneity in the heterophily scores of Senators, with some senators being more likely to follow colleagues from both political parties than others, thus providing a potential avenue for bridging the otherwise disparate Twitter "echo chambers" (Fig. 4). Senators with high heterophily scores exhibit a lesser degree of partisanship and therefore could serve as critical messengers to communicate information throughout the network. Importantly, because influence and heterophily are significantly correlated in both the communication network ( $\rho=0.53, d f=87, p$-value $<0.001)$ and the affiliation network $(\rho=0.81, d f=87, p$-value $<0.001)$, senators who are more influential also tend to be more connected to members of the other party, and thus represent important conduits of information both among and between Democrats and Republicans (Fig. 4).

\section{Interest in science is low but shows strong differences} between political parties

An analysis of a subset of Twitter accounts representing professional scientific organizations and federal science agencies that include science as a large part of their mandate shows that they are rarely followed by senators overall (Fig. 5; Table 3), even by some members who serve on committees focused on the environment such as the U.S. Senate Committee on Environment and Public Works (Fig. 6). For example, only two senators followed any Twitter accounts associated with the National Science Foundation. An nMDS analysis (Fig. 1) shows that although Twitter accounts classified as "Media", "Politics" and "Other" yielded vectors that could not be used to distinguish between Senate Democrats and Senate Republicans, Twitter accounts classified as "Science" or "Climate" were strongly positively correlated with Senate Democrats and strongly negatively correlated with Senate Republicans (Fig. 1). On average, Senate Democrats followed three times more science-related Twitter accounts than Senate Republicans. This suggests that instead of serving as the foundation for fact-based policies that bridge the political divide, science - and notably not just science related to GCC - is becoming a highly polarized "wedge issue" in the $21^{\text {st }}$ century. While cause and effect relationships cannot be deciphered from this analysis, these results suggest circumstantially that polarization over climate change legislation has spilled over to science 


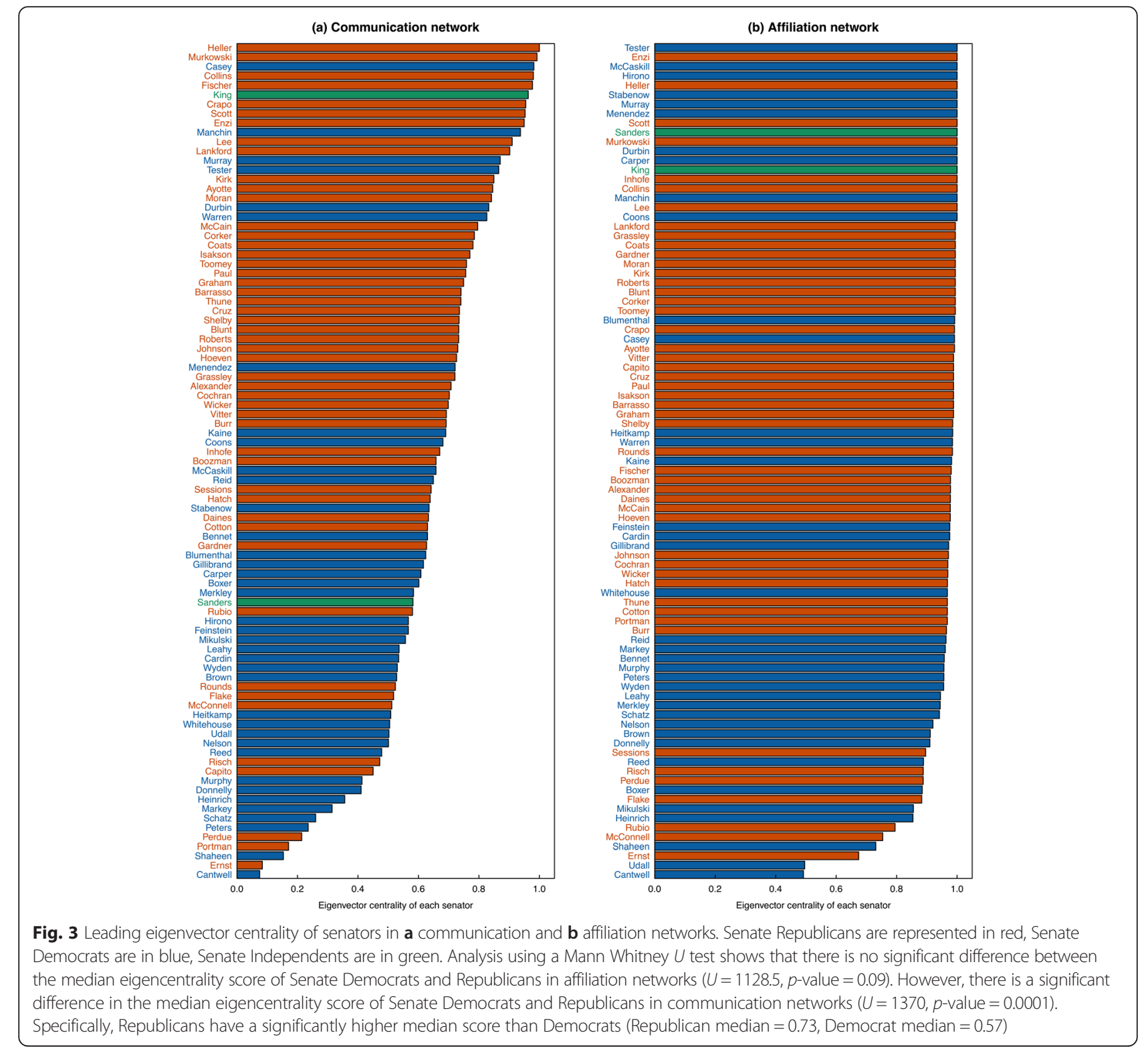

in general [23]. On average, overt, publicly displayed interest in science appears prima facie to be primarily a trait associated with Democrats. As Bob Inglis, former Republican South Carolina Congressman and founder of the Energy and Enterprise Initiative stated in a 2012 interview [25] "[...] right now it doesn't seem safe to pay attention to the science because the [conservative] ideology says no, the science is wrong." Our analysis strongly supports this statement. That said, while the divide between Senate Republicans and Senate Democrats in follows of scientific (Table 3) and climate-related (Table 4) organizations on Twitter is stark, pro-science individuals exist on both sides of the aisle (Table 5). These individuals and other conservative leaders could serve as both science advocates and important messengers of scientific information to others within their party, an idea we explore in detail below.

Table 1 One-way ANOVA relating heterophily scores of senators to party membership in the communication network. Heterophily scores were square-root transformed in order to meet the assumption of normality

\begin{tabular}{llllll}
\hline & Df & Sum Sq & Mean Sq & $F$ & $p$-value \\
\hline Party (Senate Republicans vs. Senate Democrats) & 1 & 0.0081 & 0.0081 & 0.178 & 0.674 \\
Residuals & 85 & 3.859 & 0.0454 & & \\
\hline
\end{tabular}


Table 2 One-way ANOVA relating heterophily scores of senators to party membership in the affiliation network. Heterophily scores were square-root transformed in order to meet the assumption of normality

\begin{tabular}{llcccc}
\hline & Df & Sum Sq & Mean Sq & $F$ & $p$-value \\
\hline Party (Senate Republicans vs. Senate Democrats) & 1 & 1.6 & 1.566 & 0.312 & 0.578 \\
Residuals & 85 & 427.1 & 5.024 & & \\
\hline
\end{tabular}

\section{Twitter follows serve as an indicator of senators' positions}

\section{on climate change}

Recent votes on proposed amendments to the Keystone XL pipeline bill (S.1) offer insight into how willingness of Senators to publicly identify through social media as being "pro-science" may be related to senators' understanding and acceptance of GCC, even when doing so deviates from party identity. On January 20-21, 2015, senators were asked, for the first time, to vote on a series of amendments to define the "sense of the Senate" on GCC. Amendment S.Amdt.29, proposed by Sen. Whitehouse (D-RI) and co-sponsored by well-known climate skeptic Sen. Inhofe (R-OK), simply stated that "the sense of the Senate is that climate change is real and not a hoax." It was approved by a bipartisan vote of $98-1$. A series of subsequent amendments, however, revealed differences among the senators in their positions on the role of human activity in GCC. Amendment S.Amdt.58 offered by Sen. Schatz
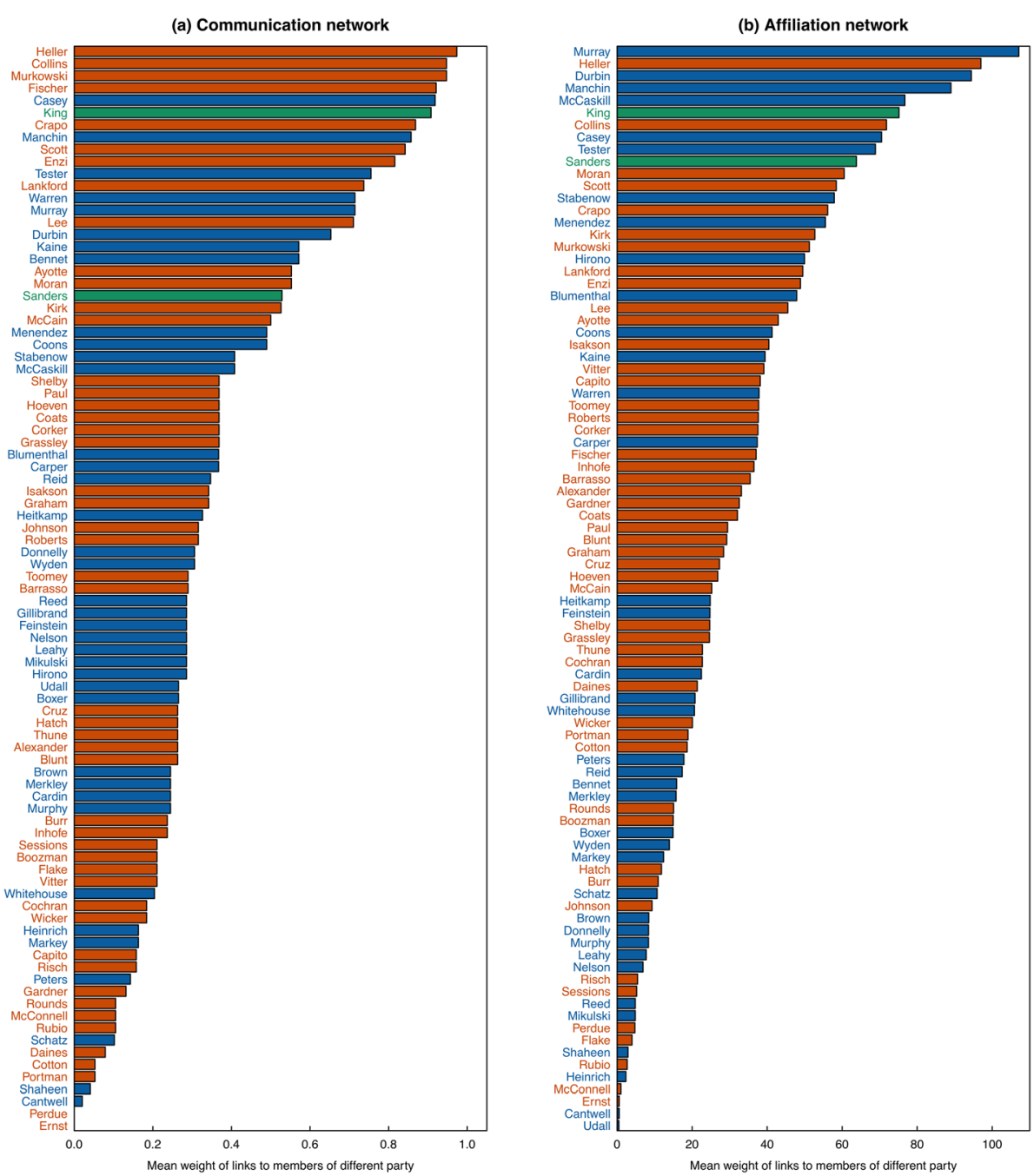

Fig. 4 Heterophily scores of senators in communication and affiliation networks. Each focal senator was assigned a heterophily score based on the mean weight of his or her links to senators from a different party in (a) direct communication and (b) indirect affiliation networks. Senate Republicans are represented in red, Senate Democrats are in blue, Senate Independents are in green. A higher value indicates a greater propensity to be connected to senators from the opposing party 


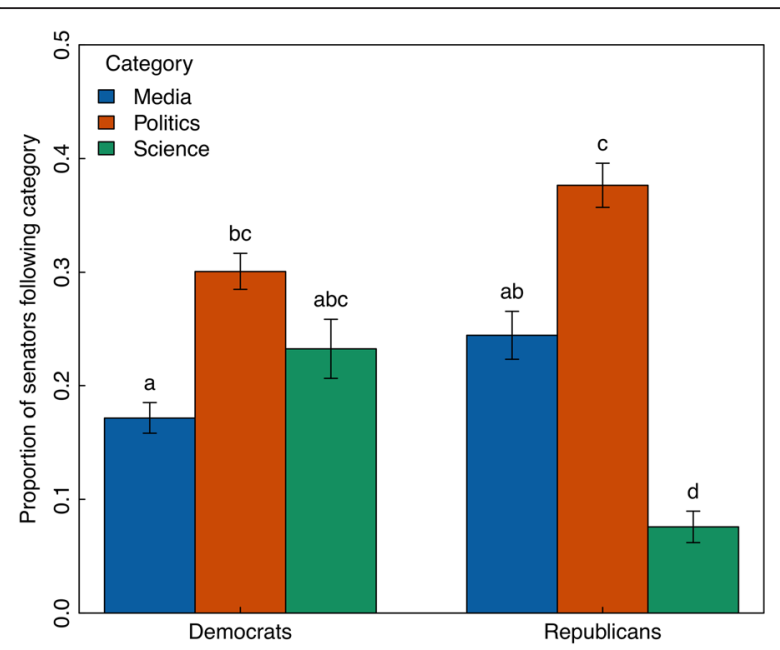

Fig. 5 Proportion of U.S. senators following Twitter accounts classified as "Media", "Politics" and "Science". Bars with distinct letters are statistically different at the $a=0.05$ level based on pairwise Mann-Whitney $U$ tests with sequential Bonferroni correction for multiple comparisons

(D-HI) clarifying that "Climate change is real and human activity significantly contributes to climate change" failed to garner the required 60 votes by a fairly wide margin (50-49), with only 2 Independents and 5 Republicans voting in favor. Sen. Hoeven (R-ND) offered a follow-up amendment (S.Amdt.87) stating that climate change is real, and that humans are contributing to it, but omitting the qualifier "significantly." (The amendment also included a statement that the Keystone XL pipeline would "not significantly worsen climate change"). The vote narrowly failed

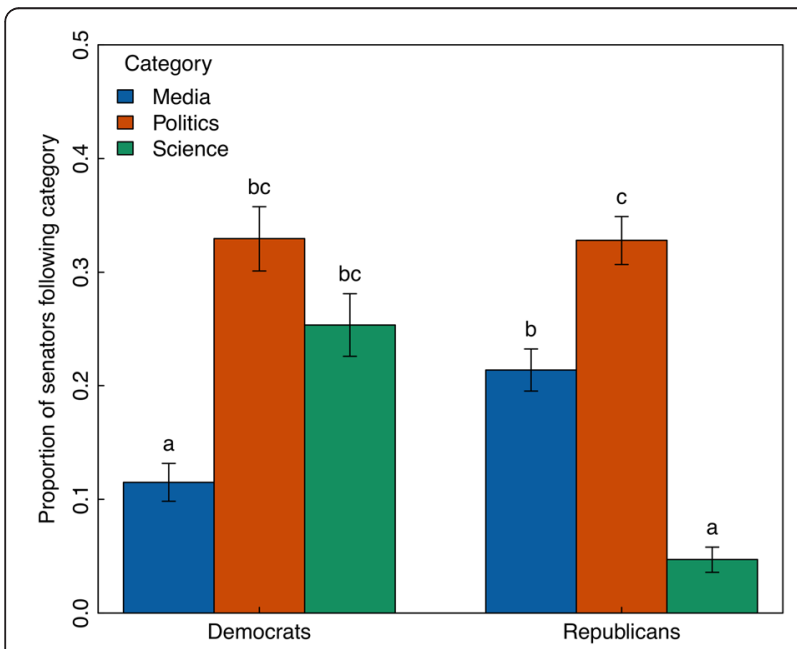

Fig. 6 Proportion of U.S. senators serving on the Committee on Environment and Public Works following Twitter accounts classified as "Media", "Politics" and "Science". Bars with distinct letters are statistically different at the $a=0.05$ level based on pairwise Mann-Whitney $U$ tests with sequential Bonferroni correction for multiple comparisons
(59 to 40 in favor), but notably "yea" votes included all Democrats, 1 Independent and 15 "crossover" Republicans. Notably, of the top 10 Republican science followers, 5 voted "yea" on the Hoeven amendment (Table 5).

Our analysis suggests that the Twitter accounts followed by senators can be used to both differentiate between Democrats and Republicans and potentially to predict their decisions on key votes. Indeed, there is a significant positive relationship between votes on the Hoeven amendment (S.Amdt.87) and senators' "Science" follows (Likelihood Ratio Test: $L R=7.02, d f=1, p$-value $=0.008$. Misclassification rate was 0.45 , mostly due to false negatives). An examination of these 15 "crossover" Senate Republicans reveals that while overall they are indistinguishable from fellow Senate Republicans in the Twitter accounts they follow, they are more similar to Senate Democrats in the number of science-related organizations that they follow than they are to their fellow Senate Republicans (Table 6). This offers some hope that exposure to or interest in science may convince senators to break from the party rank and file.

\section{Discussion}

In the face of strong polarization surrounding GCC and overall low interest and exposure to science in U.S. policy and decision-making, the scientific community is struggling to understand how communication and other barriers to science-based policy can be breached. Our analysis of social media offers insights into the potential efficacy of various pathways undertaken to bridge the partisan divide on climate change in Congress. First, several federal agencies routinely involved in policy-relevant environmental and climate science research are followed by senators from both parties and thus may serve as politically neutral messengers of government funded science and climate science in particular (Tables 3 and 4). Identifying organizations that are perceived as politically "safe," or that are connected to followers with diverse political views, may increase science communicators' ability to reach and resonate with their intended audiences. Communicating science research through these key boundary organizations [8] and working with them to better understand the perspectives of their peers may provide a crucial foot in the door for scientists. An excellent example of this is Inglis' Energy and Enterprise Initiative [26], designed to create a "safe space for conservatives to pay attention to science". The Initiative works not to convince conservatives of scientific results, per se, but speaks to the reasons why paying attention to science is important within the context of conservative values and public image.

In the same regard, some science- and climate-related agencies and boundary organizations appear to be followed by one party more than the other, offering the 
Table 3 Top ten most followed science-related Twitter accounts by U.S. senators. Data were extracted from 89 senators comprising 49 Republicans and 38 Democrats

\begin{tabular}{|c|c|c|c|c|c|c|c|c|c|}
\hline & Republicans & \# of follows & $\%$ of group & Democrats & \# of follows & $\%$ of group & Crossovers & \# of follows & $\%$ of group \\
\hline 1. & House Committee on Natural Resources & 11 & 22 & U.S. Environmental Protection Agency ${ }^{a}$ & 20 & 52 & National Park Service & 4 & 27 \\
\hline 2. & U.S. Department of Interior ${ }^{\mathrm{a}}$ & 7 & 14 & U.S. Department of Interior $^{\mathrm{a}}$ & 17 & 45 & FEMA $^{a}$ & 3 & 20 \\
\hline 3. & National Park Service & 7 & 14 & U.S. Department of Education & 15 & 39 & United Nations & 3 & 20 \\
\hline 4. & U.S. Department of Agriculture ${ }^{a}$ & 7 & 14 & U.S. Department of Agriculture ${ }^{a}$ & 14 & 37 & U.S. Department of Energy ${ }^{a}$ & 2 & 13 \\
\hline 5. & FEMA $^{a}$ & 6 & 12 & U.S. Department of Energy ${ }^{a}$ & 13 & 34 & $\begin{array}{l}\text { U.S. Environmental Protection } \\
\text { Agency }^{\mathrm{a}}\end{array}$ & 2 & 13 \\
\hline 6. & $N A S A^{a}$ & 6 & 12 & FEMA $^{a}$ & 11 & 29 & U.S. Department of Interior ${ }^{a}$ & 2 & 13 \\
\hline 7. & $N_{A A A}{ }^{a}$ & 6 & 12 & $\mathrm{NASA}^{\mathrm{a}}$ & 11 & 29 & $\mathrm{NASA}^{\mathrm{a}}$ & 2 & 13 \\
\hline 8. & U.S. Environmental Protection Agency ${ }^{a}$ & 5 & 10 & Dept. of Interior Secretary Sally Jewell ${ }^{\mathrm{b}}$ & 10 & 26 & $\begin{array}{l}\text { House Committee of Natural } \\
\text { Resources }\end{array}$ & 2 & 13 \\
\hline 9. & U.S. Department of Energy ${ }^{a}$ & 4 & 8 & U.S. EPA Administrator Gina McCarthy & 9 & 24 & $\mathrm{NOAA}^{\mathrm{a}}$ & 2 & 13 \\
\hline 10. & National Hurricane Center (Atlantic) & 4 & 8 & $\mathrm{NOAA}^{\mathrm{a}}$ & 8 & 21 & $\begin{array}{l}\text { Dept. of Interior Secretary Sally } \\
\text { Jewell }^{\mathrm{b}}\end{array}$ & 2 & 13 \\
\hline
\end{tabular}

Also shown are follows by 15 "Crossover" Republicans (who are also included in overall Senate Republican statistics) who crossed party lines to vote with Democrats on the Hoeven amendment. ${ }^{\text {TTwitter accounts }}$ followed by both Senate Democrats and Republicans ${ }^{b}$ Followed by Senate Democrats and Crossover Republicans 
Table 4 Top five most followed climate-related Twitter accounts by U.S. senators

\begin{tabular}{|c|c|c|c|c|c|c|c|c|c|}
\hline & Republicans & \# of follows & $\%$ of group & Democrats & \# of follows & $\%$ of group & Crossovers & \# of follows & $\%$ of group \\
\hline 1. & $N A S A^{a, b}$ & 6 & 12 & $\begin{array}{l}\text { U.S. Environmental Protection } \\
\text { Agency }{ }^{\mathrm{a}, \mathrm{b}}\end{array}$ & 20 & 53 & U.S. Department of Energy ${ }^{a, b}$ & 2 & 13 \\
\hline 2. & NOAA $A^{a, b}$ & 6 & 12 & U.S. Department of Energy ${ }^{\mathrm{a}, \mathrm{b}}$ & 13 & 34 & U.S. Environmental Protection Agency ${ }^{a, b}$ & 2 & 13 \\
\hline 3. & U.S. Environmental Protection Agency ${ }^{\mathrm{a}, \mathrm{b}}$ & 5 & 10 & $N A S A^{a, b}$ & 11 & 29 & $N A S A^{a, b}$ & 2 & 13 \\
\hline 4. & U.S. Department of Energy ${ }^{\mathrm{b}}$ & 4 & 8 & NOAA ${ }^{a, b}$ & 8 & 21 & $N O A A^{a, b}$ & 2 & 13 \\
\hline 5. & U.S. Geological Survey ${ }^{a, b}$ & 2 & 4 & Sierra Club & 8 & 21 & U.S. Geological Survey ${ }^{a, b}$ & 2 & 13 \\
\hline
\end{tabular}

Data were extracted from 89 senators comprising 49 Republicans and 38 Democrats. Also shown are follows by 15 "Crossover" Republicans (who are also included in overall Senate Republican statistics) who crossed party lines to vote with Democrats on the Hoeven amendment. ${ }^{a}$ Twitter accounts followed by both Senate Democrats and Republicans; ${ }^{\mathrm{b}}$ Followed by Senate Democrats and Crossover Republicans 
Table 5 Top 10 Science Followers in the U.S. Senate as of February 2015

\begin{tabular}{ll}
\hline Democrats & Republicans \\
\hline Whitehouse $^{\mathrm{a}, \mathrm{b}}(0.47)$ & Heller $^{\mathrm{b}}(0.25)$ \\
Hirono $^{\mathrm{a}, \mathrm{b}}(0.43)$ & Cochran $(0.16)$ \\
Murray $^{\mathrm{a}, \mathrm{b}}(0.29)$ & Moran $(0.10)$ \\
Markey $^{\mathrm{a}, \mathrm{b}}(0.26)$ & Crapo $(0.08)$ \\
Durbin $^{\mathrm{a}, \mathrm{b}}(0.23)$ & Kirk $^{\mathrm{a}, \mathrm{b}}(0.08)$ \\
Gillibrand $^{\mathrm{a}, \mathrm{b}}(0.17)$ & Vitter $(0.08)^{\mathrm{a}}$ \\
Stabenow $^{\mathrm{a}, \mathrm{b}}(0.17)$ & Collins \\
McCaskill $^{\mathrm{a}, \mathrm{b}}(0.06)$ \\
Blumenthal $^{\mathrm{a}, \mathrm{b}}(0.14)$ & Inhofe $^{\mathrm{a}}(0.05)$ \\
Carper $^{\mathrm{a}, \mathrm{b}}(0.13)$ & Murkowski $^{\mathrm{b}}(0.05)$ \\
\hline
\end{tabular}

"Senators who voted "yea" on the Schatz amendment (S.Amdt.58) and bSenators who voted "yea" the Hoeven amendment (S.Amdt.87). Numbers in parentheses indicate proportion of "Science" Twitter follows by each Senator, calculated as Total number of Science Twitter handles followed by that Senator/Total number of Science Twitter handles followed by all Senators

opportunity to connect science with specific social, economic, and environmental values (Tables 3 and 4). The potential value of these relationships for improving science communication and environmental stewardship cannot be overstated. For instance, in recent years some global environmental NGOs have fostered innovative relationships with major corporations by communicating and valuing the numerous benefits of better environmental stewardship, ultimately benefiting the agendas and sustainability of both [27]. Our analyses revealed that NOAA's National Hurricane Center and FEMA were among the top 10 most highly followed science accounts among Senate Republicans (Table 3). Both of these entities are routinely involved with research to understand and also prepare for natural hazards that threaten the nation's coastlines and nearby societies. This supports the idea that framing climate change as a legitimate harm to our nation's safety and wellbeing is an effective strategy for

Table 6 Correlations in follows of Science Twitter accounts between Democrats, Republicans, and Republican "Crossovers" who crossed party lines to vote "Yea" on the Hoeven amendment to the Keystone $\mathrm{XL}$ bill stating that humans contribute to Global Climate Change

\begin{tabular}{lcc}
\hline & Federal Science Agencies & Science NGOs \\
\hline Republicans vs. Democrats & 0.610 & 0.339 \\
Republicans vs. Crossovers & 0.684 & 0.621 \\
Democrats vs. Crossovers & 0.687 & 0.459
\end{tabular}

The correlation in the number of non-federal scientific organizations (Science NGOs) followed between Crossovers and Democrats is greater than that between Republicans and Democrats. The correlation in the number of Federal Science Agencies followed between Democrats and Crossovers is almost equal to that between Republicans and Crossovers. All correlations are significant at the $a=0.05$ level based on 999 Monte Carlo randomizations shifting attitudes and motivating more conservative senators to take action $[28,29]$.

\section{Conclusions}

The political divide over public understanding of global climate change in the U.S. has been well established $[12,13,23,30]$. In broader society, the higher prevalence of climate denial among Republicans than Democrats has been shown to persist despite personal experiences with climate extremes [31, 32] and coincides with a wellorganized climate change counter-movement [33, 34]. However, the way in which exposure to scientific information influences climate policy decisions remains unclear, especially when its transmission relies on non-scientific media [23]. The results of our study emphasize that members of the U.S. Congress may not be just simply interpreting information related to GCC and science in general based on their political belief systems; instead, our results suggest that more likely they are receiving such information from almost completely different sources and that overt interest in scientific organizations may now conflict with partisan identity. Although the Twitter accounts may not be directly managed by Senators themselves, but rather their staff, social media accounts nevertheless reflect the public profile of Senate offices with some accounts having many thousands of followers. Further insight is needed to fully understand how information is received and filtered through legislative staff.

Broadly elevating science interest and making climate change a dominant legislation priority will require a major landscape shift in both Congress and broader society. Unfortunately, scientific and environmental issues are rarely at the forefront of mainstream media and political agendas, with exceptions being the aftermath of largescale disasters and major climate summits such as COP21. In these situations, which can act as "focusing events", widespread coverage by mainstream media and public discourse can lead to mobilization on both new and dormant problems [35]. Given the propensity for Twitter to be used as a primary means of following breaking events [19], communications regarding the often catastrophic impacts of GCC could use this platform as a means of connecting with audiences that otherwise may be difficult to reach. For example, while results of a recent study [31] found that partisan politics trumps exposure to climate extremes in influencing acceptance of GCC, others have emphasized the critical importance of trust in the messenger [36]. This study emphasizes the critical importance of constructing and channeling these messages to reach and resonate with each side of the aisle and delivering the message from a trusted intermediary source. It also show the utility of analyzing social media as a mechanism to objectively explore the preferences and interests. 
Table 7 Total number of Twitter accounts followed by each Senator (as of February 2015) and proportion categorized as Science, Politics, Media or Other

\begin{tabular}{|c|c|c|c|c|c|c|c|c|c|c|c|c|c|}
\hline Last Name & Party & Science & Politics & Media & Other & Total & Isakson & $R$ & 0.000 & 0.168 & 0.077 & 0.755 & 429 \\
\hline Alexander ${ }^{\mathrm{a}, \mathrm{b}}$ & $\mathrm{R}$ & 0.000 & 0.154 & 0.076 & 0.770 & 409 & Johnson & $\mathrm{R}$ & 0.000 & 0.226 & 0.066 & 0.708 & 106 \\
\hline Ayotte $^{a, b}$ & $\mathrm{R}$ & 0.002 & 0.054 & 0.015 & 0.928 & 1492 & Kaine $e^{a, b}$ & D & 0.039 & 0.376 & 0.059 & 0.527 & 205 \\
\hline Barrasso & $\mathrm{R}$ & 0.004 & 0.156 & 0.081 & 0.759 & 456 & King $^{a, b}$ & I & 0.011 & 0.252 & 0.094 & 0.644 & 449 \\
\hline Bennet $^{a, b}$ & $\mathrm{D}$ & 0.024 & 0.337 & 0.000 & 0.639 & 83 & Kirk $^{a, b}$ & $\mathrm{R}$ & 0.003 & 0.042 & 0.031 & 0.924 & 1852 \\
\hline Blumenthal $\left.\right|^{a, b}$ & $\mathrm{D}$ & 0.014 & 0.086 & 0.034 & 0.866 & 801 & Lankford & $\mathrm{R}$ & 0.002 & 0.236 & 0.046 & 0.716 & 483 \\
\hline Blunt & $\mathrm{R}$ & 0.000 & 0.009 & 0.004 & 0.987 & 6799 & Leahy $^{\mathrm{a}, \mathrm{b}}$ & D & 0.000 & 0.263 & 0.053 & 0.684 & 76 \\
\hline Boozman & $\mathrm{R}$ & 0.006 & 0.064 & 0.013 & 0.917 & 543 & Lee & $\mathrm{R}$ & 0.000 & 0.045 & 0.010 & 0.945 & 2361 \\
\hline Boxer $^{a, b}$ & $\mathrm{D}$ & 0.026 & 0.553 & 0.009 & 0.412 & 114 & Manchin $^{a, b}$ & D & 0.010 & 0.183 & 0.061 & 0.739 & 624 \\
\hline Brown $n^{a, b}$ & D & 0.023 & 0.636 & 0.000 & 0.341 & 44 & Markey ${ }^{a, b}$ & D & 0.104 & 0.114 & 0.114 & 0.668 & 193 \\
\hline Burr & $\mathrm{R}$ & 0.000 & 0.006 & 0.004 & 0.990 & 3358 & McCain ${ }^{b}$ & $\mathrm{R}$ & 0.000 & 0.113 & 0.099 & 0.788 & 335 \\
\hline Cantwella & $D$ & 0.000 & 0.002 & 0.002 & 0.997 & 579 & McCaskill ${ }^{a, b}$ & D & 0.008 & 0.060 & 0.046 & 0.886 & 1434 \\
\hline Capito & $\mathrm{R}$ & 0.002 & 0.041 & 0.042 & 0.916 & 935 & McConnell & $\mathrm{R}$ & 0.000 & 0.019 & 0.000 & 0.981 & 266 \\
\hline $\operatorname{Cardin}^{\mathrm{a}, \mathrm{b}}$ & $D$ & 0.023 & 0.137 & 0.046 & 0.795 & 263 & Menendez & $D$ & 0.014 & 0.157 & 0.049 & 0.780 & 586 \\
\hline Carper $^{\mathrm{a}, \mathrm{b}}$ & D & 0.020 & 0.126 & 0.024 & 0.830 & 493 & Merkley $^{\mathrm{a}, \mathrm{b}}$ & $D$ & 0.011 & 0.282 & 0.080 & 0.626 & 174 \\
\hline Casey $^{a, b}$ & D & 0.024 & 0.277 & 0.051 & 0.648 & 412 & Mikulski ${ }^{\mathrm{a}, \mathrm{b}}$ & D & 0.000 & 0.486 & 0.000 & 0.514 & 35 \\
\hline Coats & $\mathrm{R}$ & 0.000 & 0.108 & 0.039 & 0.853 & 619 & Moran & $R$ & 0.003 & 0.031 & 0.022 & 0.945 & 2977 \\
\hline Cochran & $\mathrm{R}$ & 0.025 & 0.113 & 0.020 & 0.842 & 488 & Murkowskib & $\mathrm{R}$ & 0.009 & 0.251 & 0.037 & 0.704 & 459 \\
\hline Collins ${ }^{a, b}$ & $\mathrm{R}$ & 0.005 & 0.119 & 0.042 & 0.833 & 929 & Murphy $y^{a, b}$ & D & 0.000 & 0.128 & 0.016 & 0.856 & 125 \\
\hline Coons $^{a, b}$ & D & 0.000 & 0.035 & 0.004 & 0.961 & 2108 & Murray & D & 0.010 & 0.056 & 0.030 & 0.904 & 2171 \\
\hline Corker $^{\mathrm{b}}$ & $\mathrm{R}$ & 0.002 & 0.121 & 0.078 & 0.799 & 447 & Nelson $^{a, b}$ & $D$ & 0.080 & 0.010 & 0.060 & 0.850 & 100 \\
\hline Cotton & $\mathrm{R}$ & 0.006 & 0.154 & 0.025 & 0.815 & 356 & Paul $^{b}$ & $\mathrm{R}$ & 0.000 & 0.165 & 0.090 & 0.745 & 357 \\
\hline Crapo & $\mathrm{R}$ & 0.014 & 0.259 & 0.021 & 0.706 & 436 & Perdue & $\mathrm{R}$ & 0.000 & 0.008 & 0.000 & 0.992 & 2868 \\
\hline Cruz & $\mathrm{R}$ & 0.000 & 0.010 & 0.002 & 0.988 & 7694 & Peters ${ }^{a, b}$ & $\mathrm{D}$ & 0.009 & 0.070 & 0.029 & 0.893 & 345 \\
\hline Daines & $\mathrm{R}$ & 0.004 & 0.106 & 0.013 & 0.877 & 527 & Portman ${ }^{b}$ & $\mathrm{R}$ & 0.000 & 0.014 & 0.020 & 0.967 & 1613 \\
\hline Donnelly ${ }^{a, b}$ & D & 0.004 & 0.035 & 0.007 & 0.954 & 283 & Reed $^{a, b}$ & D & 0.000 & 0.733 & 0.000 & 0.267 & 15 \\
\hline Durbin $^{a, b}$ & $\mathrm{D}$ & 0.011 & 0.061 & 0.041 & 0.887 & 1605 & Reid $^{a, b}$ & $\mathrm{D}$ & 0.039 & 0.340 & 0.013 & 0.608 & 153 \\
\hline Enzi & $\mathrm{R}$ & 0.002 & 0.233 & 0.035 & 0.730 & 514 & Risch & $R$ & 0.023 & 0.535 & 0.000 & 0.442 & 43 \\
\hline Ernst & $\mathrm{R}$ & 0.000 & 0.011 & 0.000 & 0.989 & 89 & Roberts & $\mathrm{R}$ & 0.003 & 0.096 & 0.043 & 0.858 & 697 \\
\hline Feinstein $^{\mathrm{a}, \mathrm{b}}$ & D & 0.023 & 0.445 & 0.102 & 0.430 & 128 & Rounds $^{\mathrm{b}}$ & $\mathrm{R}$ & 0.000 & 0.316 & 0.045 & 0.639 & 155 \\
\hline Fischer & $\mathrm{R}$ & 0.000 & 0.773 & 0.008 & 0.220 & 132 & Rubio & $\mathrm{R}$ & 0.000 & 0.001 & 0.002 & 0.997 & 2726 \\
\hline Flake $^{b}$ & $\mathrm{R}$ & 0.000 & 0.038 & 0.014 & 0.947 & 208 & Sanders ${ }^{\mathrm{a}, \mathrm{b}}$ & 1 & 0.008 & 0.033 & 0.045 & 0.914 & 1688 \\
\hline Gardner & $\mathrm{R}$ & 0.002 & 0.093 & 0.039 & 0.867 & 646 & Schatz ${ }^{a, b}$ & D & 0.002 & 0.012 & 0.004 & 0.982 & 1337 \\
\hline Gillibrand $^{a, b}$ & $\mathrm{D}$ & 0.031 & 0.165 & 0.021 & 0.783 & 419 & Scott & $\mathrm{R}$ & 0.000 & 0.042 & 0.009 & 0.948 & 2784 \\
\hline Graham a,b & $\mathrm{R}$ & 0.000 & 0.024 & 0.009 & 0.967 & 2186 & Sessions & $\mathrm{R}$ & 0.000 & 0.069 & 0.088 & 0.843 & 102 \\
\hline Grassley & $\mathrm{R}$ & 0.000 & 0.003 & 0.001 & 0.996 & 14559 & Shaheen ${ }^{a, b}$ & D & 0.000 & 0.001 & 0.001 & 0.998 & 3317 \\
\hline Hatch $^{\text {b }}$ & $\mathrm{R}$ & 0.000 & 0.166 & 0.046 & 0.788 & 151 & Shelby & $\mathrm{R}$ & 0.000 & 0.250 & 0.033 & 0.717 & 244 \\
\hline Heinrich $^{a, b}$ & $\mathrm{D}$ & 0.040 & 0.360 & 0.040 & 0.560 & 25 & Stabenow $w^{\mathrm{a}, \mathrm{b}}$ & D & 0.006 & 0.030 & 0.018 & 0.946 & 2298 \\
\hline Heitkamp pa,b & D & 0.005 & 0.055 & 0.021 & 0.917 & 422 & Tester ${ }^{\mathrm{a}, \mathrm{b}}$ & D & 0.007 & 0.134 & 0.027 & 0.833 & 754 \\
\hline Heller $^{b}$ & $\mathrm{R}$ & 0.004 & 0.031 & 0.016 & 0.949 & 4934 & Thune & $\mathrm{R}$ & 0.003 & 0.141 & 0.052 & 0.804 & 306 \\
\hline Hirono $^{a, b}$ & $\mathrm{D}$ & 0.028 & 0.063 & 0.042 & 0.866 & 1185 & Toomey & $\mathrm{R}$ & 0.001 & 0.091 & 0.026 & 0.882 & 871 \\
\hline Hoeven & $\mathrm{R}$ & 0.000 & 0.142 & 0.071 & 0.787 & 409 & Udall ${ }^{\mathrm{a}, \mathrm{b}}$ & D & 0.000 & 0.400 & 0.000 & 0.600 & 5 \\
\hline Inhofe & $\mathrm{R}$ & 0.003 & 0.050 & 0.024 & 0.923 & 1370 & Vitter & $\mathrm{R}$ & 0.001 & 0.013 & 0.009 & 0.976 & 6175 \\
\hline
\end{tabular}

Table 7 Total number of Twitter accounts followed by each Senator (as of February 2015) and proportion categorized as Science, Politics, Media or Other (Continued) 
Table 7 Total number of Twitter accounts followed by each Senator (as of February 2015) and proportion categorized as Science, Politics, Media or Other (Continued)

\begin{tabular}{lllllll}
\hline Warren $^{\mathrm{a}, \mathrm{b}}$ & $\mathrm{D}$ & 0.000 & 0.336 & 0.004 & 0.660 & 238 \\
Whitehouse $^{\mathrm{a}, \mathrm{b}}$ & $\mathrm{D}$ & 0.026 & 0.037 & 0.015 & 0.921 & 1371 \\
Wicker $^{\mathrm{a}}$ & $\mathrm{R}$ & 0.011 & 0.191 & 0.046 & 0.752 & 282 \\
Wyden $^{\mathrm{a}, \mathrm{b}}$ & $\mathrm{D}$ & 0.017 & 0.057 & 0.030 & 0.896 & 299 \\
\hline
\end{tabular}

Republican senators who crossed party lines to vote "yea" on the "Schatz and/or ${ }^{b}$ Hoeven amendments are indicated

\section{Methods}

\section{Data acquisition}

We recorded the 78,753 unique Twitter accounts followed by the 89 U.S. senators of the $114^{\text {th }}$ Congress whose profiles were publicly available in February 2015. Ten senators did not maintain Twitter accounts and one (Senator Franken) followed such a large number of accounts (over 47,000 handles) that this account was deemed an unreliable indicator of interests. We classified the Twitter accounts followed by senators as "Science" if they represented nonpartisan, not-for-profit entities that included scientific research as a significant part of their mandate, "Political" if they represented either politicians or their staffers, "Media" if they represented media agencies or personalities, and "Other" if they represented individuals or other institutions from the public. The latter included partisan think tanks and any organizations with a stated political leaning. We further classified any of the handles as "Climate" if they were members of the U.S. Climate Action Network [37] or explicitly mentioned climate science, policy, or action in their profile description or associated website. Accounts were included in the analysis only if they were followed by at least one senator (Table 7).

\section{Data analysis \\ Network analysis}

We performed a suite of network analyses on the Twitter accounts followed by at least $10 \%$ of all senators using the igraph package for $\mathrm{R}$ [38]. This $10 \%$ threshold reduced the total number of unique Twitter accounts followed by the senators to 688, making network analysis and interpretation more feasible. Importantly, the results presented here hold for thresholds ranging between $5 \%$ to $10 \%$. We began by using the Twitter data to represent a "communication network" via an unweighted and undirected graph, with edges or links representing direct connections between senators. An adjacency matrix $A$ was constructed to describe whether each senator in row $i$ followed or was followed by each senator in column $j$. If the senator in row $i$ followed the senator in column $j$ or vice versa, senators $i$ and $j$ were assumed to be connected and we set $A(i, j)=A(j, i)=1$. All other entries in
$A$ were set to zero. We then built an "affiliation network" based on the Twitter accounts followed by the senators. Specifically, we built a bipartite graph and then used a one-mode projection to generate a (simply) weighted and undirected graph where the weight of the edges or links between the senators indicates the number of times a common association is found in the network of Twitter accounts that they follow.

We used a community detection algorithm based on the leading eigenvector centrality [39] to document the degree of compartmentalization by identifying distinct clusters of senators in both the communication and the affiliation networks (i.e., groups of senators that were more connected to each other than to others). Other community detection algorithms based on random walks [40] and multi-level modularity optimization [41] yielded identical results. Furthermore, we used Monte Carlo simulations to determine whether the degree of compartmentalization or modularity observed in the networks was significant. Specifically, we generated 999 random networks by shuffling the accounts that each senator follows and then computed the modularity. We then calculated the $p$-value as the proportion of random networks whose modularity was greater than or equal to that observed in the original (non-shuffled) community or affiliation network.

We were particularly interested in determining whether these distinct clusters or communities could be used to predict senator party affiliation because such an association would suggest the potential for strong echo chamber effects. To do so, we conducted a $\chi^{2}$ test to determine whether there was an association between senator party affiliation and their assigned cluster obtained via the community detection algorithm. We also computed each senator's heterophily score by determining the average weight of their links to senators from other parties.

To determine whether our pruning strategy affected the results, we re-ran the analyses by excluding only singletons (i.e., Twitter accounts followed by only one senator instead of $10 \%$ of senators). This yielded a bipartite affiliation network with 9397 unique Twitter accounts. Using this much larger network, we were able to recover all of our main results: the affiliation network was significantly compartmentalized $(p<0.001$ based on randomized networks via Monte Carlo simulations), with Senate Democrats and Republicans belonging to semi-isolated subnetworks. Indeed, party affiliation was a significant predictor of network clustering, correctly identifying $97 \%$ of Senate Democrats and 88 \% of Senate Republicans.

To determine whether the distribution of follows differed between Senate Republicans and Democrats, we tested whether the parties differed in terms of the mean (ANOVA) and the variance (Levene Test) of edge weights in the affiliation network. We found no 
significant difference in either the mean $\left(\mathrm{F}_{1,85}=0.275\right.$, $P$-value $=0.601)$ or the variance $\left(\mathrm{F}_{1,85}=3.1826, P\right.$-value $=$ 0.078 ) of edge weights between parties. Hence, there is no evidence of systematic differences in the location or the dispersion of the subnetworks formed by Senate Republicans and Democrats. This means that there is no evidence that Republicans use more varied scientific sources compared to Democrats. The communication network analysis remained unaffected by pruning since it was based on direct follows between senators and thus not subject to the initial $10 \%$ cutoff. Overall, these analyses suggest that our results are robust to our pruning process.

\section{Ordination analysis}

We conducted a non-metric Multidimensional Scaling analysis (nMDS) of the Twitter accounts followed by Senate Republicans, Democrats and Independents in order to determine whether party affiliation was associated with distinct sets of Twitter account follows. This unconstrained ordination was performed using the Jaccard index to measure the dissimilarities between senators in terms of the Twitter accounts that they followed using the vegan package for $R$ [42]. Jaccard's index was used because it is ideal for quantifying dissimilarities in presenceabsence or binary data [43]. The ordination patterns reported in the text also hold for other popular metrics such as Bray-Curtis dissimilarity.

In order to understand the differences between Senate Democrats and Republicans, we correlated the number of twitter accounts classified as "Media", "Politics", "Science" "Climate" and "Other" followed by each senator against the ordination axes using the envfit function in the vegan package for $R$ [42].

\section{Acknowledgements}

We thank the editor and anonymous reviewers for their thoughtful input into this manuscript. This is publication 335 of Northeastern University's Marine Science Center.

\section{Funding}

This project was supported by internal funding from Northeastern University's Urban Coastal Sustainability Initiative. SBS was supported by a National Science Foundation SEES Fellowship (OCE-1215825). TCG was supported by a National Science Foundation CyberSEES award (CCF-1442728).

\section{Availability of data and supporting materials}

All data (information on Twitter accounts followed by U.S. Senators) are available in Northeastern University's Digital Repository Service (DRS), http://hdl.handle.net/2047/D20207325.

\section{Authors' contributions}

$\mathrm{BH}$ led the study and the writing team; TCG performed the data acquisition from Twitter and analysis; all authors contributed to interpretation of the data and writing of the paper. All authors read and approved the final manuscript.

\section{Competing interests}

The authors declare that they have no competing interests.

Received: 5 February 2016 Accepted: 13 May 2016

Published online: 30 May 2016

\section{References}

1. Dilling $L$, Lemos MC. Creating usable science: opportunities and constraints for climate knowledge and their implications for science policy. Glob Environ Chang. 2010:21:680-9.

2. Petes LE, Howard JF, Helmuth BS, Fly EK. Science integration into US climate and ocean policy. Nat Clim Chang. 2014:4:671-7.

3. Fisher DR, Waggle J, Leifeld P. Where does political polarization come from? Locating polarization with the US climate change debate. Am Behav Sci. 2013;57:70-92.

4. McGregor G. Climatology in support of climate risk management: A progress report. Prog Phys Geogr. 2015;39:536-53.

5. Selkoe KA, Blenckner T, Caldwell MR, Crowder LB, Erickson AL, Essington TE, Estes JA, Fujita RM, Halpern BS, Hunsicker ME, et al. Principles for managing marine ecosystems prone to tipping points. Ecosyst Health Sustain. 2015;1:17.

6. Deng B: US lawmakers advance controversial science-policy bill. Nature News. 2015. doi:10.1038/nature.2015.17430.

7. Morello L: US lawmakers approve controversial spending bill. Nature News 2015. doi:10.1038/nature.2015.17696.

8. Tribbia J, Moser SC. More than information: what coastal managers need to plan for climate change. Environ Sci Pol. 2008;11:315-28.

9. Mooney C. The Republican War on Science. New York: Basic Books; 2006.

10. Fisher M: The Republican party isn't really the anti-science party. Atlantic 2013.

11. Gordon G. Politicization of science in the public sphere: A study of public trust in the United States, 1974 to 2010. Am Sociol Rev. 2012;77:167-87.

12. Leiserowitz A, Maibach E, Roser-Renouf C, Feinberg G, Howe P. Climate change in the American mind: Americans' global warming beliefs and attitudes in April, 2013. New Haven, CT: Yale Project on Climate Change Communication; 2013.

13. McCright AM, Dunlap RE. The politicization of climate change and polarization in the American public's views of global warming, 2001-2010. Sociol Q. 2011:52:155-94.

14. Carl N, Cofnas N, Woodley MA. Scientific literacy, optimism about science and conservatism. Personal Individ Differ. 2016:94:299-302.

15. Hutto CJ, Yardi S, Gilbert E. A longitudinal study of follow predictors on Twitter. In: CHI'13 Proceedings of the SIGCHI Conference on Human Factors in Computing Systems. 2013.

16. Barberá P, Jost JT, Nagler J, Tucker JA, Bonneau R. Tweeting From left to right: Is online political communication more than an echo chamber? Psychol Sci. 2015;26:1531-42.

17. Golbeck J, Grimes JM, Rogers A. Twitter use by the U.S. Congress. J Am Soc Inf Sci Technol. 2010;61:1612-21.

18. Eysenbach G. Can tweets predict citations? Metrics of social impact based on Twitter and correlation with traditional metrics of scientific impact. J Med Int Res. 2011;13:e123.

19. Barthel M, Shearer E, Gottfried J, Mitchell A: The evolving role of news on Twitter and Facebook. Pew Research Center. http://www.journalism.org/ 2015/07/14/the-evolving-role-of-news-on-twitter-and-facebook/Accessed 9 Dec 2015.

20. Jasny L, Waggle J, Fisher DR. An empirical examination of echo chambers in US climate policy networks. Nat Clim Chang. 2015;5:782-6.

21. Nisbet EC, Cooper KE, Garrett RK. The partisan brain: How dissonant science messages lead conservatives and liberals to (dis)trust science. Ann Am Acad Pol Soc Sci. 2015;658:36-66.

22. Blank JM, Shaw D. Does partisanship shape attitudes toward science and public policy? The case for ideology and religion. Ann Am Acad Pol Soc Sci. 2015;658:18-35.

23. Hmielowski JD, Feldman L, Myers TA, Leiserowitz A, Maibach E. An attack on science? Media use, trust in scientists, and perceptions of global warming. Public Underst Sci. 2013;23:866-83.

24. Conover MD, Gonçalves B, Ratkiewicz J, Francisco M, Flammini A, Menczer F. Political polarization on Twitter, Proceedings of the 5th International Conference on Weblogs and Social Media. 2011.

25. http://www.pbs.org/wgbh/pages/frontline/environment/climate-of-doubt/ bob-inglis-climate-change-and-the-republican-party/Accessed 1 May 2016.

26. http://republicen.org/Accessed 1 May 2016

27. Kareiva PM, McNally BW, McCormick S, Miller T, Ruckelshaus M. Improving global environmental management with standard corporate reporting. Proc Natl Acad Sci. 2015;112:7375-82.

28. Nisbet MC. Communicating Climate Change: Why Frames Matter for Public Engagement. Environment. 2015;51:12-23. 
29. Nisbet MC, Mooney C. Framing Science. Science. 2007;316:56

30. McCright AM, Dunlap RE. Defeating Kyoto: The conservative movement's impact on US climate change policy. Soc Probl. 2003;50:348-73.

31. Marquart-Pyatt ST, McCright AM, Dietz T, Dunlap RE. Politics eclipses climate extremes for climate change perceptions. Glob Environ Chang. 2014;29:246-57.

32. McCright AM, Dunlap RE, Xiao C. The impacts of temperature anomalies and political orientation on perceived winter warming. Nat Clim Chang. 2014;4:1077-81.

33. Brulle RJ. Institutionalizing delay: foundation funding and the creation of US climate change counter-movement organizations. Clim Chang. 2014;122:681-94.

34. Oreskes N, Conway EM. Merchants of doubt: How a handful of scientists obscured the truth on issues from tobacco smoke to global warming. USA: Bloomsbury Publishing; 2011.

35. Birkland T. Focusing events, mobilization, and agenda setting. J Public Policy. 1998:18:53-74.

36. Anderson AA, Myers TA, Maibach EW, Cullen H, Gandy J, Witte J, Stenhouse $\mathrm{N}$, Leiserowitz A. If they like you, they learn from you: How a brief weathercaster-delivered climate education segment Is moderated by viewer evaluations of the weathercaster. Weather Climate Soc. 2013;5:367-77.

37. http://www.usclimatenetwork.org/ Accessed 9 Dec 2015).

38. Csardi G, Nepusz T. The igraph software package for complex network research. InterJ Complex Syst. 2006;1695:1-9.

39. Newman ME. Finding community structure in networks using the eigenvectors of matrices. Phys Rev E. 2006;74:036104.

40. Pons $P$, Latapy M. Computing communities in large networks using random walks. J Graph Algorithms Appl. 2006;10:191-218.

41. Blondel VD, Guillaume J-L, Lambiotte R, Lefebvre E. Fast unfolding of communities in large networks. J Stat Mech: Theory Exp. 2008;2008:P10008.

42. Oksanen J, Blanchet FG, Kindt R, Legendre P, Minchin PR, O'Hara RB, Simpson GL, Solymos P, Stevens MHH, Wagner H. Vegan: Community Ecology Package. 2013

43. Legendre L, Legendre P. Numerical Ecology. 2nd ed. Amsterdam: Elsevier Science; 1998

\section{Submit your next manuscript to BioMed Central and we will help you at every step:}

- We accept pre-submission inquiries

- Our selector tool helps you to find the most relevant journal

- We provide round the clock customer support

- Convenient online submission

- Thorough peer review

- Inclusion in PubMed and all major indexing services

- Maximum visibility for your research

Submit your manuscript at www.biomedcentral.com/submit 